\title{
Decontamination of N95 Respirators using Moist Heat Delivered by Hospital Blanket Warming Cabinets: A Widely Available Method for N95 Re- Processing
}

\section{Anand Kumar ( $\nabla$ akumar61@yahoo.com )}

University of Manitoba

\section{Samantha B. Kasloff}

National Microbiology Laboratory, Public Health Agency of Canada

\section{Todd Cutts}

National Microbiology Laboratory, Public Health Agency of Canada Anders Leung

National Microbiology Laboratory, Public Health Agency of Canada Naresh Sharma

University of Manitoba

\section{Gloria Vazquez-Grande}

University of Manitoba

\section{Tracy Drew}

National Microbiology Laboratory, Public Health Agency of Canada

\section{Denis Laframboise}

National Microbiology Laboratory, Public Health Agency of Canada

Olivero Orofino

National Microbiology Laboratory, Public Health Agency of Canada Joe Tanelli

National Microbiology Laboratory, Public Health Agency of Canada Jay Krishnan

National Microbiology Laboratory, Public Health Agency of Canada

\section{Research Article}

Keywords: Decontamination, N95 Respirators, Moist Heat, Warming

Posted Date: March 11th, 2021

DOI: https://doi.org/10.21203/rs.3.rs-273466/v1 
License: (c) (i) This work is licensed under a Creative Commons Attribution 4.0 International License. Read Full License 


\section{Abstract}

Shortages of personal protective equipment for use during the SARS-CoV-2 pandemic continue to be an issue among health-care workers globally. Extended and repeated use of N95 filtering facepiece respirators without adequate decontamination is of particular concern. Although several methods to decontaminate and re-use these masks have been proposed, logistic or practical issues limit adoption of these techniques. In this study, we propose and validate the use of the application of moist heat $\left(70^{\circ} \mathrm{C}\right.$ with humidity augmented by an open pan of water) applied by commonly available hospital (blanket) warming cabinets to decontaminate N95 masks. This report shows that a variety of N95 masks can be repeatedly decontaminated of SARS-CoV-2 over 6 hours moist heat exposure without compromise of their filtering function as assessed by standard fit and sodium chloride aerosol filtration efficiency testing. This approached can easily adapted to provide point-of-care N95 mask decontamination allowing for increased practical utility of mask recycling in the health care setting.

\section{Introduction}

With COVID19 disease activity again reaching new heights throughout the world, extreme shortages of personal protective equipment (PPE), particularly N95 filtering facepiece respirators (FFP) continue to present a substantial obstacle to provision of care[1,2]. We have recently published data showing the relative utility of seven different decontamination techniques to support reuse of N95 respirators beyond their normal single use standard[3]. Several of the assessed decontamination methods are viable in a hospital setting using a centralized processing approach. However, these centralized approaches involving collection of $\mathrm{N} 95$ respirators for off-site processing followed by return and re-allocation to endusers frequently do not allow easy return of decontaminated respirators to their original user. Understandably, many health care workers have been reluctant to use a respirator that was previously utilized by another worker. Here we report a simple decontamination method using a hospital blanket warming cabinet that could potentially be implemented at the local ward level and would substantially reduce logistic management issues allowing easy return of decontaminated respirators to their previous users.

In our previous paper, we demonstrated moist heat application of $75^{\circ} \mathrm{C}$ for 3 hours was sufficient to fully eliminate viable SARS-CoV-2 from N95 respirator material[3]. Moist heat can easily be provided using standard heating cabinets (often used for warming blankets) found on most clinical wards in North American and European hospitals. However, only a minority of these devices are designed to achieve temperatures of $75^{\circ} \mathrm{C}$ or more. To our knowledge, virtually all models of generic medical warming cabinets (excluding those designed specifically for warming intravenous fluids and medications) can achieve a temperature of at least $70^{\circ} \mathrm{C}$. We sought to determine whether the application of moist heat at $70^{\circ} \mathrm{C}$ could decontaminate 6 different types of N95 respirators experimentally contaminated with SARSCoV-2 without degrading fit and filtration efficiency over a series of decontamination cycles 


\section{Materials And Methods}

\section{N95 Respirators}

Six different respirators were evaluated; because of their scarcity, most of them were obtained from two local hospitals after they had been grommeted for fit testing. They included three molded and three pleated types. Molded types included the 1860, 8210 (3M Company, St. Paul, MN) and 1510 (Moldex, Culver City, CA) models; the pleated included the Aura 1870, Vflex 1804 (3M Company, St. Paul, MN) and Pleats Plus 1054 (Aearo Company, Indianapolis) models.

\section{Heat Treatment of Respirators}

To create a heating chamber akin to a hospital blanket warmer in a high containment (BSL-3) laboratory, a two shelved, 57 L Model BD 56 standard incubator (BINDER Inc., Bohemia, NY) with its temperature set at $70^{\circ} \mathrm{C}$ was used. A small pan ( 6 inch X 6 inch, 2 inch depth) filled with water was placed below the bottom shelf the night before the experiment to sustain relative humidity $(\mathrm{RH})$ at the highest level achievable passively. Temperature and $\mathrm{RH}$ were recorded using EL-USB-2 Temperature \& Humidity Data Logger, (Lascar electronics, Erie, PA). For fit testing and integrity testing, whole respirators were exposed to the moist heat by placing them on the shelves and leaving them there for a continuous 6 hours.

\section{Quantitative Fit Testing}

Quantitative fit testing was performed in a small room $\left(500 \mathrm{ft}^{3}\right)$ using a PortaCount ${ }^{\circledR}$ Pro+ Respirator Fit Tester Model 8038 and FitPro+ ${ }^{\mathrm{TM}}$ Fit Test software (TSI Incorporated, Shoreview, MN). An ultrasonic room humidifier (Honeywell, Charlotte, North Carolina) was used to generate aerosol particles for the testing. The quantitative fit test was performed as per CSA Z94.4-18 protocol[4], where the ratio of particles inside the respirator to the number of particles outside the respirator was determined to calculate the fit factor by the software. Seven well defined exercises were performed as part of this standardized test: normal breathing, deep breathing, turning head side to side, moving the head up and down, reading a standardized passage aloud, bending up and down, and normal breathing. A respirator that scores a fit factor of minimum 100 for each of the exercises and an average of 100 more was considered a pass $[5,6]$.

\section{Filter integrity testing}

Metal grommets used for fit testing were sealed with glue on the outer and inner surfaces before testing. Filtration efficiency testing was performed using the $\mathrm{NIOSH}$ sodium chloride $(\mathrm{NaCl})$ aerosol method on a TSI 8130A Automated Filter Tester[7,8]. Respirators were fastened to a $3 \mathrm{~mm}$ thick aluminum disk using $3 \mathrm{M} 3792 \mathrm{LM}$ hot melt glue, and allowed to fully set for 20 minutes before being loaded into the TSI 8130A. Respirators were challenged for 5 minutes at a flow rate of $85 \pm 4 \mathrm{~L} / \mathrm{min}$ with an aerosol of $\mathrm{NaCl}$ particles at a concentration not exceeding $200 \mathrm{mg} / \mathrm{m}^{3}$.

\section{Assessment of SARS-CoV-2 Inactivation with Dry and Moist Heat Treatments}


To determine whether several hours of exposure to dry or moist heat at $70^{\circ} \mathrm{C}$ would inactivate SARS-CoV2 , small swatches cut from each of the 6 respirators were surface contaminated with SARS-CoV-2 virus inoculum. The inoculum was prepared by mixing the virus in a standard tripartite organic soil load (bovine serum albumin, tryptone, and mucin) as per ASTM standard to mimic body fluids[9]. Ten $\mu$ l of the inoculum estimated to contain approximately $5.0 \log \mathrm{TCID}_{50}$ of SARS-CoV-2 was spotted onto the outer surface of each respirator swatch at 3 different positions. Following 60 minutes of drying, they were placed on the two shelves of the incubator and left there for 6 uninterrupted hours. Corresponding positive control respirator swatches were concurrently spotted with the same viral inoculum, dried under the biosafety cabinet for an hour, and processed for virus titer determination to account for the effect of drying on virus recovery.

Following heat treatment, virus was eluted from the respirator material by excising the spotted areas on each respirator swatch and transferring each into $1 \mathrm{ml}$ of virus culture medium (DMEM with $2 \%$ fetal bovine serum and $1 \%$ penicillin-streptomycin). After 10 minutes of soaking and elution of the material by repeated pipetting, the entire eluate from each excised coupon was transferred to each well of a Vero seeded 6-well plate. Plates were incubated for up to 1 week for signs (CPE) of viral growth. Eluates recovered from positive control coupons were used for viral titer determination in $\mathrm{TCID}_{50}$ per Reed and Muench[10]. Results for each treatment indicate mean \pm standard deviations of three biological replicates.

\section{Temperature and $\mathrm{RH}$ recorded inside sterilization pouch and paper bag}

In real-world application methods, individual N95 respirators would be placed in steam sterilization pouches or paper bags before placing in the warming cabinets. To mimic this, a temperature/RH logger was placed inside several types of bags in order to ascertain that a N95 respirator in a bag or bags in a warming cabinet would be exposed to the appropriate temperature-humidity profile. The first logger was placed inside a steam sterilization pouch (Chex-All® II Instant Sealing Pouch, Propper Manufacturing Company, Long Island City, NY) that was sealed before placing in the warming cabinet. Similarly, another logger was placed inside a single paper grocery-size bag (brown single-layer 140 GSM Kraft paper), its opening folded once and a piece of tape was used to keep the fold in place. In the third configuration, a logger was placed inside two bags; first by bagging in a lunch-size bag (brown single-layer $120 \mathrm{GSM}$ Kraft paper), the opening of which was once folded closed, then placing the smaller bag inside another paper grocery-size bag as before, the opening of which closed in the same manner as before (figure 1).

\section{Results}

\section{Recovery of SARS-CoV-2 from N95 Respirator swatches}

High titers of infectious virus were recovered from all six untreated control N95 respirators (figure 2); interestingly, recovery was slightly better $\left(4.62 \pm 0.1 \mathrm{TCID}_{50}\right)$ from molded respirators in comparison to pleated ones $\left(4.44 \pm 0.1 \mathrm{TCID}_{50}\right)$, statistically insignificant. 


\section{Viral Inactivation by Dry or Moist Heat Treatments}

Dry heat and relative humidity data measured from the middle shelf of the incubator without the pan of water showed the temperature and $\mathrm{RH}$ plateau at $71.5^{\circ} \mathrm{C}$ and $3.5 \%$ respectively (figure 2 ). Initial experimental attempts performed using SARS-CoV-2 contaminated N95 respirator swatches that are exposed to the dry heat failed to inactivate infectious virus, even after 8 hours of exposure (table 1). Placement of a pan of water at the bottom of the incubator has increased the $\mathrm{RH}$ to $32 \%$ in 2 hours (figure 2); interestingly, the peak temperature has dropped to $67^{\circ} \mathrm{C}$. Even though 8 hours of dry heat treatment failed to inactivate SARS-CoV-2 on the respirator swatches, 6 hours of moist heat treatment was sufficient to completely inactivate SARS-COoV-2 virus from all of the 6 respirator materials. Three hours of moist heat treatment could not inactivate any of the N95 swatches.

Table 1: Efficacy of heat treatments in decontaminating N95 respirators contaminated with SARS-CoV-2

\begin{tabular}{|c|c|c|c|c|c|}
\hline \multirow[t]{2}{*}{ N95 Respirator } & \multirow[t]{2}{*}{ Unexposed } & \multicolumn{2}{|c|}{ Dry heat } & \multicolumn{2}{|c|}{ Moist heat } \\
\hline & & $6 \mathrm{hr}$ & $8 \mathrm{hr}$ & $3 \mathrm{hr}$ & $6 \mathrm{hr}$ \\
\hline 3M Aura 1870 &,,+++ &,,+++ &,,+++ &,,+++ & 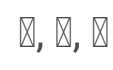 \\
\hline Pleats Plus 1054 &,,+++ & $\nabla_{,}+,+$ & $\nabla_{1}+,+$ &,,+++ & 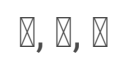 \\
\hline 3M Vflex 1804 &,,+++ & $\nabla_{1}+,+$ & $\nabla_{1}+,+$ &,,+++ & 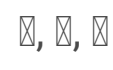 \\
\hline 3M 1860 &,,+++ &,,+++ &,,+++ &,,+++ & 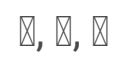 \\
\hline Moldex 1510 &,,+++ & $\nabla,+,+$ &,,+++ &,,+++ & 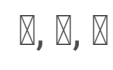 \\
\hline $3 M 8210$ &,,+++ & $\nabla, \nabla,+$ &,,+++ &,,+++ & $\mathbb{Q}, \mathbb{Q}, \mathbb{\nabla}$ \\
\hline
\end{tabular}

+ viral growth present, $\otimes$ no viral growth present; each + or $\otimes$ sign represents presence/absence of viral growth from a triplicate set of $\mathrm{N} 95$ respirator swatches.

\section{Impact of moist heat on structural and functional integrity}

Moist heat treatment did not result in any noticeable change as assessed by visual or tactile inspection. In addition, all 6 respirators preserved structural and functional integrity of respirators as assessed by PortaCount quantitative fit testing after up to 5 rounds of moist heat treatments (Table 2 and 3 ).

Table 2: Average fit factor before and after moist heat treatments 


\begin{tabular}{|llll|}
\hline Average Fit Factor* & & & \\
\hline Manufacture, Model & Untreated & $\begin{array}{l}\text { Moist Heat }\left(70^{\circ} \mathrm{C} \text { X } 6 \text { hr }\right) \\
1 \text { treatment }\end{array}$ & $\begin{array}{l}\text { Moist Heat } \\
\left(70^{\circ} \mathrm{C} \times 6 \mathrm{hr}\right) 5 \text { treatments }\end{array}$ \\
\hline 3M Aura 1870 & 186 & 371 & 324 \\
\hline Pleats Plus, 1054 & 226 & 326 & 382 \\
\hline 3M Vflex 1804 & 134 & 135 & 274 \\
\hline 3M 1860 & 141 & 106 & 110 \\
\hline Moldex 1510 & 224 & 378 & 229 \\
\hline 3M 8210 & 205 & 303 & 398 \\
\hline
\end{tabular}

*a minimum fit factor of 100 is required to pass the test

Table 3: Filtration Efficiency Testing Results of N95 Respirators after Repeat Decontamination Cycles

\begin{tabular}{|lllll|}
\hline & Untreated & \multicolumn{3}{l|}{$\begin{array}{l}\text { Moist heat } \mathbf{7 0} \mathbf{0}^{\circ} \mathbf{X} \mathbf{6} \text { hrs, } \\
\mathbf{5} \text { treatments }\end{array}$} \\
\hline Manufacturer & $\begin{array}{l}\text { Pressure Drop } \\
(\mathrm{Pa})\end{array}$ & $\begin{array}{l}\text { Filtration } \\
\text { Efficiency }\end{array}$ & $\begin{array}{l}\text { Pressure Drop } \\
(\mathrm{Pa})\end{array}$ & $\begin{array}{l}\text { Filtration } \\
\text { Efficiency }\end{array}$ \\
\hline 3M Aura 1870 & 76 & $99.7 \%$ & 69 & $100 \%$ \\
\hline $\begin{array}{l}\text { Pleats Plus } \\
\text { 1054 }\end{array}$ & 27 & $98.6 \%$ & 29 & $97.7 \%$ \\
\hline 3M Vflex 1804 & 48 & $99.7 \%$ & 39 & $98.3 \%$ \\
\hline 3M 1860 & 82 & $99.6 \%$ & 76 & $98.9 \%$ \\
\hline Moldex 1510 & 114 & $98.8 \%$ & 107 & $97.8 \%$ \\
\hline 3M 8210 & 76 & $99.4 \%$ & 78 & $99.5 \%$ \\
\hline
\end{tabular}

\section{Discussion}

In view of the current heavy demand for extended PPE options, methods to decontaminate N95 respirators for re-use is an area of intense review. Although we (and others), have demonstrated several effective approaches to respirator sterilization and re-deployment[3,11], most methods still have logistic or practical disadvantages that may limit their uptake in the real world. For example the use of UV respirator treatment is limited by the availability of appropriate UV lamps and concern about their ability to deliver sterilization beyond the exposed respirator surface[3]. Autoclave treatment is broadly available but utility is limited to a subset of pleated (rather than molded) construction[3,12]. Vaporized or gaseous 
hydrogen peroxide methods require relatively expensive and complex devices that may be in limited supply in the current circumstance. Low temperature hydrogen peroxide gas plasma treatment (STERRAD) is effective for at least one standard cycle or two express cycles but damages N95 respirators beyond that $[3,13]$. Peracetic acid (PAA) fogging may be a viable methodology but is not well known, and aeration of residual PAA is required before mask re-use. In addition, as a non-standard method, there is no commercial application device for PAA fogging. Use of the technique requires a customized approach in which the necessary elements are assembled and a standard operating procedure developed. A practical issue with all these methods relates to the logistic impediment of collecting respirators for off-site processing and subsequent re-distribution. An additional and substantial problem is that clinical experience has shown that $\mathrm{N} 95$ respirator users have a strong aversion to re-using respirators utilized by others despite their sterilization (i.e. the "ick" factor). Therefore, all these sterilization methods are only likely to be successful if the logistics of processing allows for the return of FFPs to their original user. A potential solution would be a highly localized (ward level) sterilization process where the individual user can be assured that they are re-using the same respirator.

Many viruses, particularly enveloped viruses, are known to be sensitive to the application of moist heat (sub-boiling point heat with an elevated $\mathrm{RH}$ ). Exposure to temperatures of 55 to $95^{\circ} \mathrm{C}$ for relatively brief periods of minutes to hours can result in inactivation of a large range of human and animal viral pathogens with higher temperatures being associated with more rapid inactivation [14-17]. Among the human viral pathogens sensitive to heat of $<100^{\circ} \mathrm{C}$ are influenza viruses, vaccinia virus, adenoviruses, rotavirus, hepatitis $C$ virus, norovirus and poliovirus among many other human pathogens $[16,18,19]$. Similarly, many viruses including influenza are inactivated more effectively with increased ambient humidity[20,21]. Of particular interest, both human and animal coronaviruses are both temperature and humidity sensitive[17,22,23]. They can, as a consequence, be rapidly inactivated by moist heat treatment[14,23]. MERS-CoV causing Middle Eastern Respiratory Syndrome and SARS-Co-V causing Severe Acute Respiratory Syndrome have been shown to be inactivated by temperatures of $56-65^{\circ} \mathrm{C}$ for varying durations of 15 minutes to 2 hours with increased inactivation with increased humidity [24-27]. Thermal inactivation of SARS-CoV-2 has also been documented on several different surfaces with increased ambient humidity augmenting thermal viral inactivation [28-31].

Our data demonstrate that exposure of SARS-CoV-2-contaminated N95 filtering facepiece respirators to a temperature of $70^{\circ} \mathrm{C}$ in the presence of passive humidity for 6 hours is highly effective for thermal inactivation of the virus. For a viable, simple, scalable but local solution to the problem of $\mathrm{N} 95$ respirator decontamination, it is necessary to consider the aversion of HCWs to re-use of respirators previously utilized by others. While the substantial logistical problem of collecting N95 respirators for offsite decontamination processing is an issue, returning decontaminated respirators to the same end-user may be a near impossible challenge under the current levels of hospital system stress. Fortunately, the decontamination approach described here lends itself to easy adoption in hospitals and other institutions. Heating cabinets used for warming blankets are ubiquitous in hospitals and health care institutions throughout the developed world. All the commonly used models are designed to deliver a 
temperature of at least $70^{\circ} \mathrm{C}$. While they do not typically offer humidity control, we have demonstrated that the placement of a shallow basin filled with water will consistently yield a relative humidity of more than $20 \%$. As we have shown, used N95 respirators (even contained in a paper bag) exposed to the interior of such a cabinet should be effectively decontaminated with 6 hours exposure. Using this method, each HCW can manage decontamination and re-use of their own respirator in their local work site within their typical workshift duration of 8-12 hours.

Our study suggests SARS-CoV-2 decontamination of respirators requires more time at $70^{\circ} \mathrm{C}$ than might be expected based on other studies that did not use any organic soil load[28]. Our results generated using SARS-CoV-2 virus mixed with a standard tripartite soil load are more representative of the clinical environment. Most other studies that have examined thermal inactivation of SARS-CoV-2 have not been designed to specifically address the question of N95 respirator decontamination and therefore used different surfaces to assess decontamination[32]. However, virus inactivation efficiency is partially dependent on the medium in which or surface on which the virus is suspended or located[32]. Further, in other cases the ambient humidity was either not noted or was not augmented[30]. Although soiling of the contaminated specimen with biological fluids and mimics containing proteins tend to be protective of viruses[17,33], no studies of $\mathrm{N} 95$ respirators utilized soiling as might be expected on used respirators. The recent study by Daeschler and colleagues[28], for example, demonstrated that a $70^{\circ} \mathrm{C}$ with $0 \%$ relative humidity exposure of an hour was sufficient to drive viable virus to undetectable levels on contaminated N95 respirator coupons. However, their coupons were contaminated with SARS-CoV-2 virus without soiling. In a previous study, we demonstrated that exposure of a similar coupon where the inoculum was prepared by mixing the virus in a tripartite soil load (bovine serum albumin, tryptone, and mucin) as per ASTM standard to mimic body fluids[9] failed to fully inactive the inoculum with $3 \mathrm{hrs}$ exposure to $70^{\circ} \mathrm{C}$ with $22 \%$ humidity[3]. Therefore, our results indicating a requirement for 6 hours exposure to $70^{\circ} \mathrm{C}$ with $22 \% \mathrm{RH}$ may better indicate the necessary exposure parameters to effect decontamination in the clinical scenario where some degree of soiling with saliva would be expected.

This should allow for more enthusiastic uptake of a decontamination and re-use approach to increase effective N95 supply. Point-of-care (local ward) level decontamination methods could substantially reduce logistic management issues (collection of $\mathrm{N} 95$ respirators for off-site processing followed by reallocation to end-users) and increase the probability of uptake of a decontamination and re-use approach to increase effective N95 supply.

\section{References}

1. Ranney ML, Griffeth V, Jha AK (2020) Critical Supply Shortages - The Need for Ventilators and Personal Protective Equipment during the Covid-19 Pandemic. New England Journal of Medicine 382: e41.

2. Andrew J (2020) Health Care Workers Still Face Daunting Shortages of Masks and Other P.P.E. The New York Times. New York, NY. 
3. Kumar A, Kasloff SB, Leung A, Cutts T, Strong JE, et al. (2020) Decontamination of N95 masks for reuse employing 7 widely available sterilization methods. PLoS One 15: e0243965.

4. Canada SCo (2018) CAN/CSA-Z94.4-18: Selection, use and care of respirators; 5th edition. CSA Group. pp. 163.

5. Bergman MS, Viscusi DJ, Zhuang Z, Palmiero AJ, Powell JB, et al. (2012) Impact of multiple consecutive donnings on filtering facepiece respirator fit. American Journal of Infection Control 40: 375-380.

6. Bergman M, Zhuang Z, Brochu E, Palmiero A (2015) Fit assessment of N95 filtering-facepiece respirators in the US Centers for Disease Control and Prevention Strategic National Stockpile. Journal of the International Society for Respiratory Protection 32: 50-64.

7. Rengasamy S, Shaffer R, Williams B, Smit S (2017) A comparison of facemask and respirator filtration test methods. Journal of occupational and environmental hygiene 14: 92-103.

8. (NIOSH) NIfOSaH (2019) Procedure No. TEB-APR-STP-0059, Revision 3.2. Determination of particulate filter efficiency level for N95 series filters against solid particulates for non-powered, airpurifying respirators standardtesting procedure (STP).

9. Sattar SA, Springthorpe VS, Adegbunrin O, Zafer AA, Busa M (2003) A disc-based quantitative carrier test method to assess the virucidal activity of chemical germicides. Journal of Virological Methods 112: 3-12.

10. Reed LJ, Muench H (1938) A simple method of estimating fifty per cent endpoints. American journal of epidemiology 27: 493-497.

11. Steinberg BE, Aoyama K, McVey M, Levin D, Siddiqui A, et al. (2020) Efficacy and safety of decontamination for $\mathrm{N} 95$ respirator reuse: a systematic literature search and narrative synthesis. Can J Anaesth.

12. Meisenhelder C, Anderegg L, Preecha A, Ngooi CO, Liao L, et al. (2020) Effect of Dry Heat and Autoclave Decontamination Cycles on N95 FFRs. medRxiv: 2020.2005.2029.20114199.

13. (2020) Instructions for Healthcare Facilities: Decontamination of Compatible N95 Respirators in ASP STERRAD Sterilization Systems.

14. Kampf G, Voss A, Scheithauer S (2020) Inactivation of coronaviruses by heat. J Hosp Infect 105: 348-349.

15. Knight A, Haines J, Zuber S (2013) Thermal inactivation of animal virus pathogens. Curr Top Virol 11: 103-119.

16. Araud E, DiCaprio E, Ma Y, Lou F, Gao Y, et al. (2016) Thermal Inactivation of Enteric Viruses and Bioaccumulation of Enteric Foodborne Viruses in Live Oysters (Crassostrea virginica). Applied and environmental microbiology 82: 2086-2099.

17. Hessling M, Hoenes K, Lingenfelder $C$ (2020) Selection of parameters for thermal coronavirus inactivation - a data-based recommendation. GMS hygiene and infection control 15: Doc16-Doc16. 
18. Heimbuch BK, Wallace WH, Kinney K, Lumley AE, Wu CY, et al. (2011) A pandemic influenza preparedness study: use of energetic methods to decontaminate filtering facepiece respirators contaminated with H1N1 aerosols and droplets. Am J Infect Control 39: e1-9.

19. Sauerbrei A, Wutzler P (2009) Testing thermal resistance of viruses. Archives of Virology 154: 115119.

20. McDevitt J, Rudnick S, First M, Spengler J (2010) Role of absolute humidity in the inactivation of influenza viruses on stainless steel surfaces at elevated temperatures. Appl Environ Microbiol 76: 3943-3947.

21. Donaldson Al, Ferris NP (1976) The survival of some air-borne animal viruses in relation to relative humidity. Veterinary Microbiology 1: 413-420.

22. Aboubakr HA, Sharafeldin TA, Goyal SM (2020) Stability of SARS-CoV-2 and other coronaviruses in the environment and on common touch surfaces and the influence of climatic conditions: A review. Transbound Emerg Dis.

23. Casanova LM, Jeon S, Rutala WA, Weber DJ, Sobsey MD (2010) Effects of air temperature and relative humidity on coronavirus survival on surfaces. Appl Environ Microbiol 76: 2712-2717.

24. Leclercq I, Batejat C, Burguiere AM, Manuguerra JC (2014) Heat inactivation of the Middle East respiratory syndrome coronavirus. Influenza Other Respir Viruses 8: 585-586.

25. Rabenau HF, Cinatl J, Morgenstern B, Bauer G, Preiser W, et al. (2005) Stability and inactivation of SARS coronavirus. Med Microbiol Immunol 194: 1-6.

26. Van Doremalen N, Bushmaker T, Munster V (2013) Stability of Middle East respiratory syndrome coronavirus (MERS-CoV) under different environmental conditions. Eurosurveillance 18: 20590.

27. Chan KH, Peiris JS, Lam SY, Poon LL, Yuen KY, et al. (2011) The Effects of Temperature and Relative Humidity on the Viability of the SARS Coronavirus. Adv Virol 2011: 734690.

28. Daeschler SC, Manson N, Joachim K, Chin AWH, Chan K, et al. (2020) Effect of moist heat reprocessing of N95 respirators on SARS-CoV-2 inactivation and respirator function. CMAJ 192: E1189-E1197.

29. Patterson El, Prince T, Anderson ER, Casas-Sanchez A, Smith SL, et al. (2020) Methods of Inactivation of SARS-CoV-2 for Downstream Biological Assays. The Journal of Infectious Diseases 222: 1462-1467.

30. Fischer R, Morris DH, van Doremalen N, Sarchette S, Matson J, et al. (2020) Assessment of N95 respirator decontamination and re-use for SARS-CoV-2. medRxiv: 2020.2004.2011.20062018.

31. Biryukov J, Boydston JA, Dunning RA, Yeager JJ, Wood S, et al. (2020) Increasing Temperature and Relative Humidity Accelerates Inactivation of SARS-CoV-2 on Surfaces. mSphere 5.

32. Pastorino B, Touret F, Gilles M, de Lamballerie X, Charrel RN (2020) Heat Inactivation of Different Types of SARS-CoV-2 Samples: What Protocols for Biosafety, Molecular Detection and Serological Diagnostics? Viruses 12: 735.

33. Steinmann J (2001) Some principles of virucidal testing. Journal of Hospital Infection 48: S15-S17. 
Figures

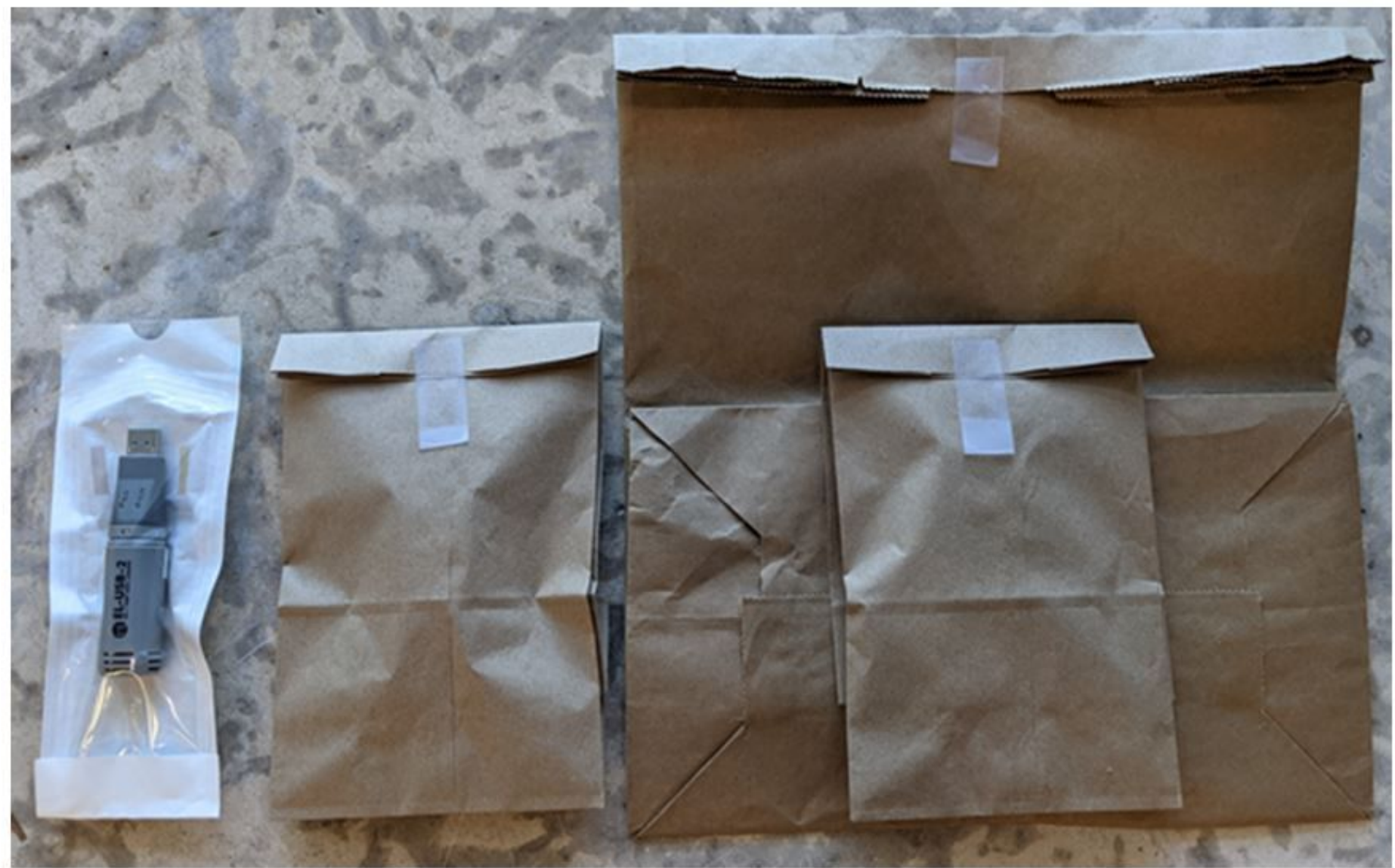

Figure 1

Sealed bags left to right: steam sterilization pouch, single layer paper bag , double layer (grocery and lunch size) paper bags 


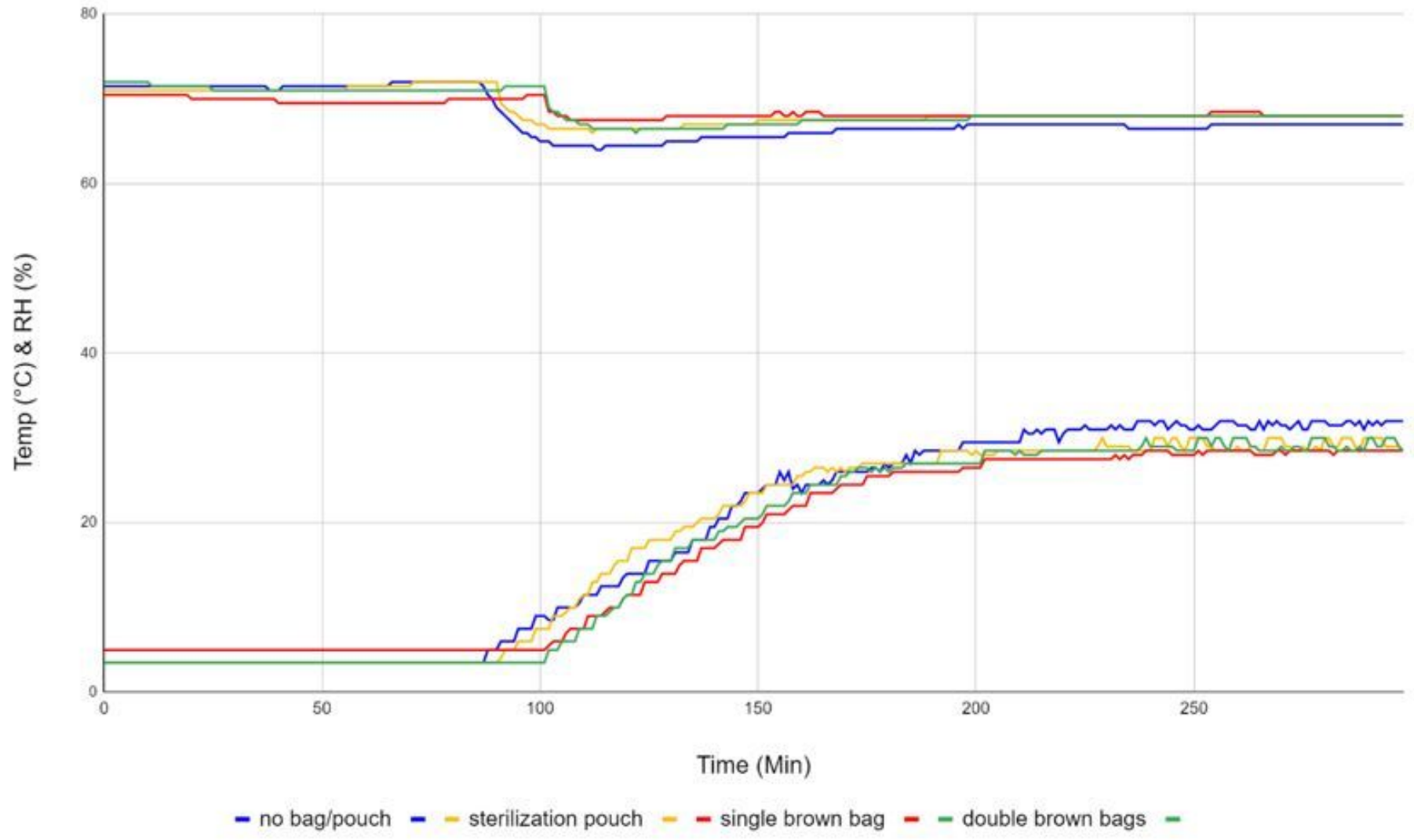

Figure 2

Temperature and relative humidity measured inside the warming cabinet when the temp/RH logger was placed inside a sterilization pouch, inside a single or double bags or no bag/pouch 